\title{
Antibiotic Resistance Pattern in Children with UTI: A Study in a Tertiary Care Hospital, Dhaka, Bangladesh
}

\author{
Md. Atiqul Islam ${ }^{1, ~ *, ~ S h e u l y ~ B e g u m ², ~ S a l i n a ~ S h a h e e n ~ P a r u l ~}{ }^{3}$, A. K. M. Tajuddin Bhuyian ${ }^{4}$, \\ Md. Tazul Islam ${ }^{5}$, Md. Kariul Islam ${ }^{6}$ \\ ${ }^{1}$ Department of Paediatric Infectious Diseases and Community Paediatrics, Dhaka Shishu (Children) Hospital, Dhaka, Bangladesh \\ ${ }^{2}$ Department of Gynaeocology \& Obstetrics, Enam Medical College, Savar, Dhaka, Bangladesh \\ ${ }^{3}$ Bio-chemistry Department, Sylhet MAG Osmani Medical College, Sylhet, Bangladesh \\ ${ }^{4}$ Dhaka Shishu (Children) Hospital, Dhaka, Bangladesh \\ ${ }^{5} 250$ Bedded General Hospital, Jamalpur, Bangladesh \\ ${ }^{6}$ International Online Journal Hub (IOJH), Dhaka, Bangladesh \\ Email address: \\ roman.atique@yahoo.com.sg (Md. A. Islam) \\ ${ }^{*}$ Corresponding author
}

\section{To cite this article:}

Md. Atiqul Islam, Sheuly Begum, Salina Shaheen Parul, A. K. M. Tajuddin Bhuyian, Md. Tazul Islam, Md. Kariul Islam. Antibiotic Resistance Pattern in Children with UTI: A Study in a Tertiary Care Hospital, Dhaka, Bangladesh. American Journal of Pediatrics. Vol. 5, No. 4, 2019, pp. 191-195. doi: 10.11648/j.ajp.20190504.14

Received: June 19, 2019; Accepted: July 31, 2019; Published: September 18, 2019

\begin{abstract}
Urinary tract infection (UTI) is one of the most common pediatric infections. It distresses the child, concerns the parents, and may cause permanent kidney damage. Occurrences of a first-time symptomatic UTI are highest in boys and girls during the first year of life and markedly decrease after that. Febrile infants younger than 2 months constitute an important subset of children who may present with fever without a localizing source. For resistance knowledge of etiology pathogens of UTIs and their antimicrobial resistance patterns in specific geographical location may help clinicians in choosing the appropriate antimicrobial. Our aim was to assess bacteriological profile and antibiotic resistance pattern in pediatric UTI. A cross sectional study was conducted at Dhaka Shishu Hospital during the period from Feb 2016 to Aug 2016 . A total of 147 culture positive UTI patient were considered for analysis. Colony counts for these samples were identified, and the profile of antibiotic resistance was identified. Here, samples with a colony count of $\geq 105 \mathrm{CFU} / \mathrm{mL}$ bacteria were considered positive. A total 147 culture positive UTI patients were enrolled. Here, Escherichia coli (E-coli) was found as the most prevalent isolates 103 (70\%) followed by Klebsiella spp. 13.6\%, Pseudomonas 5.44\%, Enterobacter spp 3.40\%, Staphylococcus Aureus 3.40\%, Proteus $2.72 \%$ and Enterococcus $1.36 \%$. Twelve (12) antimicrobial agents were used for antimicrobial susceptibility testing. The most resistant drugs we found were Colistin (CL) $(94.55 \%)$, followed by Cefradine (79.59\%), Co-trimoxazole (SXT) (69.39\%), Nalidixic acid (NA) (66.67\%) and Ceftazidime (CTM) (48.98\%). None of the drug found was $100 \%$ resistance against urinary pathogens. Antimicrobial drug resistance is decreasing among urinary pathogens. We suggest that, empirical antibiotic selection should be based on knowledge of the local prevalence of bacterial organism and their antibiotic resistance in a specific area rather than on universal or even national guidelines.
\end{abstract}

Keywords: UTI, Antibiotic Resistance, Urinary Pathogens

\section{Introduction}

Urinary tract infection (UTI) is one of the most common pediatric infections. It distresses the child, concerns the parents, and may cause permanent kidney damage.
Occurrences of a first-time symptomatic UTI are highest in boys and girls during the first year of life and markedly decrease after that. Febrile infants younger than 2 months constitute an important subset of children who may present with fever without a localizing source. The workup of fever in these infants should always include evaluation for UTI. 
UTI is the most common serious bacterial infection in infants and children both in community and hospital setting. UTI is an important cause of morbidly and mortality in children. [1-3] UTI is an infection of the lower urinary tract, the upper urinary tract, or both. [4] Boys are more susceptible during the first year of life; thereafter the incidence is substantially higher in girls. [5, 6] Rapid diagnosis and prompt antimicrobial treatment are required to minimize the related complications, such as uro-sepsis, urolithiasis and renal abscess as well as the prevention of renal scarring and permanent renal-parenchymal damage. To achieve these aims an empirical antibiotic prescription is often endorsed even before the culture results are available. On the other hand antibiotic resistance of urinary track pathogens has been known to increase worldwide, specially to commonly used antimicrobials [7-9]. The increase antibiotic resistance trends are likely to have important clinical implication for the empirical used of antibiotics. For this resistance knowledge of etiology pathogens of UTIs and there antimicrobial resistance patterns in specific geographical location may help clinicians in choosing the appropriate antimicrobial $[10,11]$. Reporting of antimicrobial susceptibility testing of the urinary tract is usually achieved 48 hours following sampling, and therefore, in the majority of UTI cases, the treatment decision is empirical, being influenced by available data reflecting antibiotic resistance. For the initiation of antimicrobial therapy in UTI knowledge of the antimicrobial resistance patterns of common uro-pathogens in each region is essential to provide appropriate therapy. Hence, there exists a great need for antimicrobial resistance surveillance at the local, national, and international levels. The effect of resistant microorganism is obvious in hospitals and other healthcare facilities, when infections caused by drag resistant microorganism. This result in a prolonged infectivity with the related mortality and mortality especially among immune compromised patients [12]. The aim of the present study was to determine the frequency of isolation and antimicrobial resistance patterns of uro-pathogens among children subjected to urine culture at Dhaka Shishu (children) Hospital, a teaching and referral hospital in Bangladesh.

\section{Objectives}

General Objective:

To assess the antibiotic resistance pattern in children with UTI (Urinary tract Infection) in Bangladesh.

Specific Objective:

To show a bacteriological profile regarding efficacy and resistance in treating children with UTI (Urinary tract infection) in Bangladesh

\section{Materials \& Methods}

This was a cross sectional study carried out in both inpatient and outpatient department in Dhaka Shishu (Children) Hospital from February 2016 to August 2016. Study specimen were cultured on MacConkey agar plates and blood agar plates by calibrated loop method. Pipetted was auto adjustable one calibrated loopful $(0.01 \mathrm{~mL})$ of wellmixed urine samples were cultured on 5\% blood agar and Mac Conkey ager plates by calibrated loop Method and incubated aerobically at $37^{\circ} \mathrm{C}$ for 24 hours. UTI was considered by the presence of a pure bacterial growth of $>105$ colony forming units $/ \mathrm{mL}$ in children with urinary symptoms such as fever $\geq 38^{\circ} \mathrm{C}$, chills, frequency, urgency, dysuria, suprapubic, and/or flank tenderness, pyuria (defined as $\geq 10$ leukocytes/hpf), and in neonates clinical evidences of sepsis. Suspected colonies were identified by colony morphology, Grams stains and biochemical testing. Data about age and sex of patients were also collected. Colony counts yielding bacterial growth of $105 \mathrm{CFU} / \mathrm{ml}$ or more were deemed significant (inclusion Criteria) for this cases the antimicrobial susceptibility test (AST) was performed by modified Kirby Bauer disc definition method on Mueller Hinton plates. Urine cultures were considered as negative when bacterial growth was lower than $103 \mathrm{CFU} / \mathrm{ml}$ (exclusion criteria). Growth of two or more bacterial species (Polymorphic bacterial growth) was considered as an exclusion criterion.

\section{Result}

A total of 147 culture positive UTI patient were considered for analysis. Among them 95 (64.6\%) was in outpatient dept. and $52(35.4 \%)$ from inpatient dept. Regarding gender and sex $90(61 \%)$ of them were girls and $57(39 \%)$ were boys, with average age of 4.5 years and 4.2 years respectively. Only $79 \%$ of our cases showed a high white blood cell count (pyuria) in urinalysis. They were further processed for identification and antibiotic susceptibility testing. The most frequently isolated bacteria included E. coli $(70 \%)$, followed by Klebsiella spp. (13.6\%), Pseudomonas aeruginosa (4.2\% each 1), Enterococcus spp. (3.40\%), Staphylococcus Aureus, Protius Spp., Enterococcu faecalis Spp. Colony counts for these samples were identified, and the profile of antibiotic resistance was identified. Here, samples with a colony count of $\geq 105 \mathrm{CFU} / \mathrm{mL}$ bacteria were considered positive. Twelve (12) antimicrobial agents were used for antimicrobial susceptibility testing. The most resistant drugs were Colistin (CL) $(94.55 \%)$, followed by Cefradine (79.59\%), Cotrimoxazole (SXT) (69.39\%) Nalidixic acid (NA) (66.67\%) and ceftazidime (CTM) (48.98\%). None of the drug found was $100 \%$ resistance against urinary pathogens.

Table 1. Distribution of patients by sex and age. $(n=147)$.

\begin{tabular}{lllll}
\hline Age & Male & \% & Female & Total \\
\hline $1-5$ yrs. & 37 & & 60 & 97 \\
$6-10$ yrs. & 20 & & 30 & 50 \\
Total & 57 & & 90 & 147 \\
\hline
\end{tabular}


Table 2. Frequency and types of bacterial isolates. $(n=147)$.

\begin{tabular}{ll}
\hline Bacterial Isolates & N (\%) \\
\hline E. Coli & $103(70 \%)$ \\
Klebsiella spp. & $20(13.6 \%)$ \\
Pseudomonus aeruginosa & $8(5.44 \%)$ \\
Enterobactor Spp. & $5(3.40 \%)$ \\
Staph aureus & $5(3.40 \%)$ \\
Protius Spp. & $4(2.72 \%)$ \\
Enterococcu faecalis Spp. & $2(1.36 \%)$ \\
Total & $147(100 \%)$ \\
\hline
\end{tabular}

Table 3. Antimicrobial Resistance (\%) of Isolated Uropathogenic Bacteria ( $n=147)$.

\begin{tabular}{llll}
\hline Name of Antibiotics & Sensitivity N & Resistant N & Resistance (\%) \\
\hline Colistin (CL) & 8 & 139 & 94.55 \\
Cefradine & 30 & 117 & 79.59 \\
Co-trimoxazole (SXT) & 45 & 102 & 69.39 \\
Nalidixic acid (NA) & 49 & 98 & 66.67 \\
Ceftazidime (CTM) & 75 & 72 & 48.98 \\
Azithromycin (AZ), & 75 & 72 & 48.97 \\
Ciprofloxacin (CP) & 93 & 54 & 36.74 \\
Nitrofurantoin (FD) & 101 & 46 & 31.29 \\
Ceftriaxone (CRO) & 119 & 28 & 19.05 \\
Amikacin (AK) & 135 & 12 & 8.16 \\
Meropenum (MP) & 138 & 9 & 6.12 \\
Imepenum (IP) & 143 & 4 & 2.72 \\
\hline
\end{tabular}

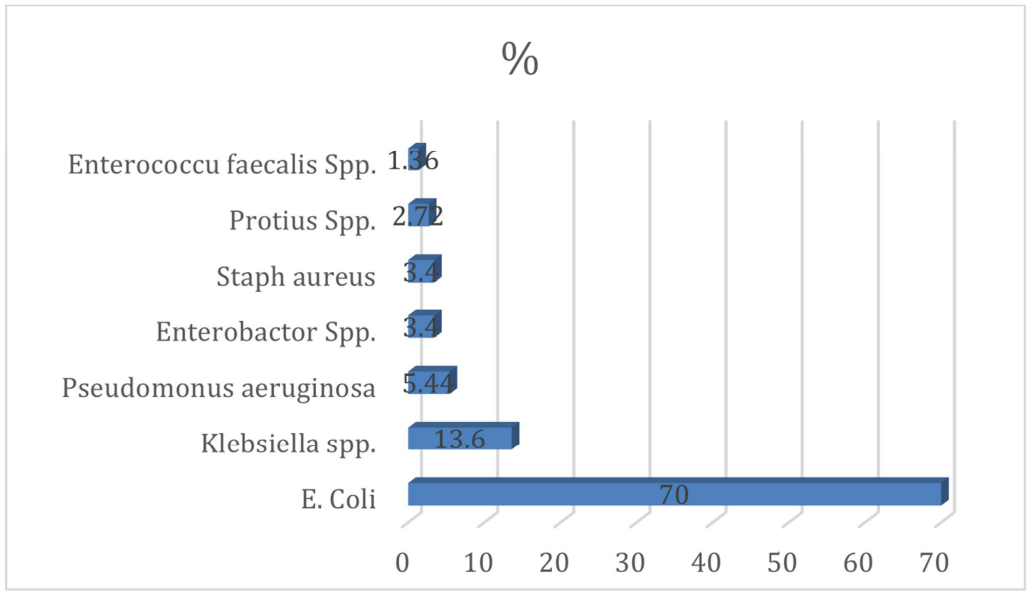

Figure 1. Distribution of bacterial resistance (\%) in organisms.

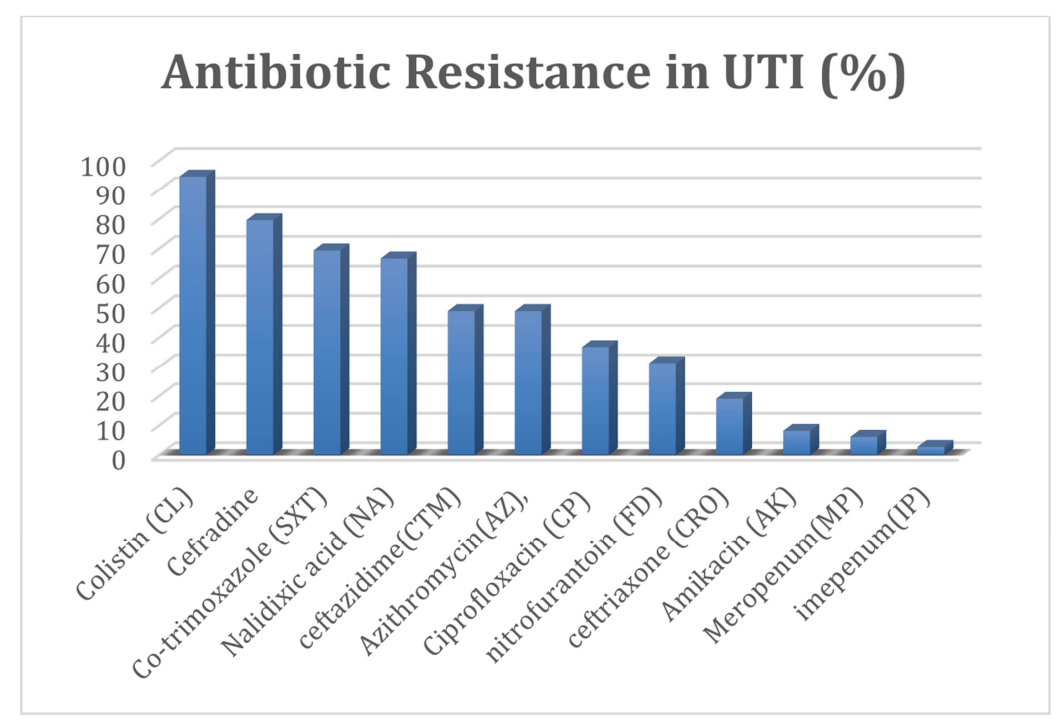

Figure 2. Antimicrobial Resistance (\%) of Isolated Uropathogenic Bacteria $(n=147)$. 


\section{Discussion}

There was no comprehensive study before this study in our country to estimate the most common uropathogens and their resistance pattern in pediatrics. Uropathogen are gaining resistance at an increased rate to commonly used antimicrobial agents. The sensitivity pattern is changing day by day and it varies from hospital to hospital. Constant survey of antimicrobial resistance is very important for empirical treatment of UTI. $[15,16]$ This study showed the prevalence of isolation and antibiotic resistance pattern of uropathogenic bacteria in a referral pediatric hospital in Dhaka shishu Hospital during 07 months period. As indicated in the previous studies, E coli and Klebsiella spp. have also been isolated as the most common pathogens responsible for UTI among children. However, E coli was the most frequent organism isolated $(71.4 \%)$. This is similar to results of investigations in other countries. [17, 18]. In this study, higher resistance rates to all antibiotics tested with the exception of amikacin, imepenum and Meropenum may be explained by high and uncontrolled usage of these antimicrobial agents, especially third-generation cephalosporins during the past few years in our country. Unfortunately, these antibiotics were widely prescribed not only for UTI but also for other infections. We could investigate the uropathogens from other parts of our country to find more accurate and more comprehensive results about etiology and their antimicrobial resistance pattern and it can be our limitation of this research. E coil is steel the most common (70\%) cause of UTI and the klebsiella being the second (13.6\%). In a study conducted in BSMMU by Abu saleh ahmed et al showed that the incidence of E coil, Klebsiellaspp, Enterobacterspp and Pseudomonas aeruginosa in UTI patients were $60.02 \%, 9.73 \%, 11.38 \%$ and $4.04 \%$ respectively. [19] In a study conducted in India in 2007 has shown the distribution of urinary pathogen as follows. E, colli 63\%, Klebsiellaspp $15.9 \%$ and Pseudomonas aeruginosa 5.30\%. [20] Another study conducted at Border guard Hospital (BGB Hospital Peel khana Dhaka) by Lt Col. Syed Nurun Nobi et al in 2013 Showed E-coli $63.26 \%$, Klebsiella $12.24 \%$ Proteus $2.77 \%$ and Pseudomonas spp $8.17 \%$. In the present study result of antibiotic susceptibility test reveal that no the urinary isolate were $100 \%$ resistance to any drugs. Previous study showed that the susceptibility of E-coli to impenum ranged from $98-100 \%$. In the present study, most of the isolates were found fairly resistance in Colistin (CL) (94.55\%), followed by Cefradine (79.59\%), Co-trimoxazole (SXT) (69.39\%) Nalidixic acid (NA) (66.67\%) and ceftazidime (CTM) (48.98\%). All the isolates showed strong resistance to Colistin and Cefradine.

\section{Limitation of this Study}

This study was done in a single centre with limited sample size and also short period of time. So, the study result may not reflect the scenarios of the whole country.

\section{Conclusion}

This study provides valuable information regarding current distribution of urinary pathogens and their antimicrobial resistance pattern. We suggest that empirical antibiotic selection should be based on knowledge of the local prevalence of bacterial organism and antibiotic resistance. UTI treatment and their use should be more judicious for definitive therapy as well as empiric treatment for patient with urinary tract infection to prevent resistance.

\section{Conflict of Interest}

Not declared

\section{Approval}

Got approval from the respective department.

\section{Acknowledgements}

The authors wish to thank the microbiology laboratory doctors \& staff, as well as the junior doctors who help me to collect data at Dhaka Shishu (Children) Hospital, for their kind support during this study.

\section{References}

[1] L PJadresić, "Diagnosis and management of urinary tract infections in children". Paediatrics and Child Health, 2010; 20 (6): 274-278.

[2] Adjei and COpoku, "Urinary tract infections in African infants," International Journal of Antimicrobial Agents, 2004; 24 (1): S32-S34.

[3] F Mortazavi and NShahin, "Changing patterns in sensitivity of bacterial uropathogens to antibiotics in children," Pakistan Journal of Medical Sciences, 2009; 25 (5): 801-805.

[4] Dulczak S, Kirk J Overview of the evaluation, diagnosis and management of urinary tract infections in infants and children. UrolNurs 2005; 25: 185-191.

[5] Larcombe J. Urinary tract infection in children. BMJ 1999; 319: 1173-1175.

[6] Alper BS, Curry SH. Urinary tract infection in children. Am Famil Phys 2005; 72: 2483-2488.

[7] F. E. Abdullah, AA, Memon, MY, Bandukda, and M Jamil, "Increasing ciprofloxacin resistance of isolates from infected urines of a cross-section of patients in Karachi," BMC Research Notes, 2012; 5 (1): 696-701.

[8] Alemu, F Moges, Y Shiferaw, K Tafess, AKassu, B. Anagaw, et al., "Bacterial profile and drug susceptibility pattern of urinary tract infection in pregnant women at University of Gondar Teaching Hospital, Northwest Ethiopia," BMC Research Notes, 2012; 5 (1): 197-204. 
[9] G. Schmiemann, I Gagyor, E Hummers-Pradier, and J. Bleidorn, "Resistance profiles of urinary tract infections in general practice-an observational study," BMC Urology, 2012; 12 (1): $33-38$.

[10] S. Farajnia, MY Alikhani, R Ghotaslou, B Naghili, and ANakhlband, "Causative agents and antimicrobial susceptibilities of urinary tract infections in the northwest of Iran," International Journal of Infectious Diseases, 2009; 13 (2): $140-144$

[11] N. Kashef, GE Djavid, and SShahbazi, "Antimicrobial susceptibility patterns of community-acquired uropathogens in Tehran, Iran," Journal of Infection in Developing Countries, 2010; 4 (4): 202-206.

[12] Pieore RK, Patrice M. Lazre K. Antibiotic resistance in E. coli isolated from women genitila and tend of minimal inhibiting concentration in a semi-urban population. Current research journal biological science 2012: 4 (16). 696-701.

[13] Clinical Laboratory Standards Institute (CLSI). Performance Standards for Antimicrobial Susceptibility Testing; Nineteenth Informational Supplement (M100-S19). Wayne, PA: CLSI; 2009.

[14] Nabi SN, Haider KMTS, Rahimgir M, Uddin MN, Shapla NR et al; "Current trends of urinary pathogens \& their antimicrobial susceptibility pattern in a tertiary care hospital," JAFMC Bangladesh. (December) 2014; 10 (2).

[15] Hryniewicz K, Szczypa K, SulikowskaA et al. Antibiotic Susceptibility of bacterial stains isolated from urinary tract infection in Polland. J. Antimicrobchemother 2001; 47 (6): 773-80.

[16] Farjana R, Sadia C, Mojibur R, Ahmed D, Anwar H. Antimicrobial resistance pattern of gram negative bacteria causing urinary tract infection, Stamford journal of Pharmaceuticals sci 2009; 2 (1): 44-50.

[17] Lizama CM, Luco IM, Reichhard TC, et al. Urinary tract infection in a pediatrics emergency department: frequency and clinical parameters. Rev ChilenaInfectol 2005; 22: 235-241.

[18] Lutter SA, Currie ML, Mitz LB, et al. Antibiotic resistance patterns in children hospitalized for urinary tract infections. Arch PediatrAdolesc Med 2005; 159: 924-928.

[19] Salah AA, Ahmed SS, Ahmed M, Naser A, Ruhul A M. Changing Trends in Uropathogens and their antimicrobial sensitivity pattern. Bangladesh J Med Microbial 2009; 03 (01); $9-12$.

[20] Tantry BA, Rahiman S. Antibacterial resistance and trend of urinary tract pathogens in commonly used antibiotics in khasmir Valley; West Indian med J 2012; 61 (7): 43-44. 